\title{
АНАЛИЗ ВЛИЯНИЯ ГЕОМЕТРИЧЕСКИХ ПАРМЕТРОВ ПОПЕРЕЧНОГО СЕЧЕНИЯ ОЧИСТНОЙ ТУПИКОВОЙ КАМЕРЫ НА ЭФФЕКТИВНОСТЬ ЕЕ ПРОВЕТРИВАНИЯ
}

\author{
Е.В. НАКАРЯКОВ \\ Горный институт УрО РАН, г. Пермь
}

\begin{abstract}
Аннотация: В работе представлены результаты математического моделирования условий проветривания протяженных тупиковых очистных камер при работе в них погрузочно-доставочных машин с двигателем внутреннего сгорания. Произведена оценка влияния различных конфигураций сечений очистной камеры на процесс выноса ядовитых примесей рудничного воздуха из пространства очистной камеры на рабочее место горнорабочего.

Ключевые слова: Тупиковые выработки, Двигатель внутреннего сгорания, Математическое моделирование, Ядовитые газы, Вентилятор местного проветривания.
\end{abstract}

В российской нормативной документации [1] отсутствуют требования по проветриванию тупиковых камерообразных выработок, образующихся за счет расширения нарезной выработки до камерообразной при обратном порядке отработки. При отработке запасов медно-никелевых руд в краевых частях шахтных полей месторождений Талнахского рудного узла (Красноярский край, г. Норильск) отсутствует возможность организации сквозного проветривания очистных камер. Общая длина тупиковых очистных камер может достигать в этом случае 30 м. В связи с недостаточностью требований нормативной документации возникает необходимость исследования эффективности выноса ядовитых примесей выхлопных газов погрузочно-доставочных машин (далее по тексту - ПДМ) из камерного пространства на рабочее место горнорабочего. Рабочее место горнорабочего расположено в разрезной выработке на сопряжении с устьем очистной камеры (рис. 1).

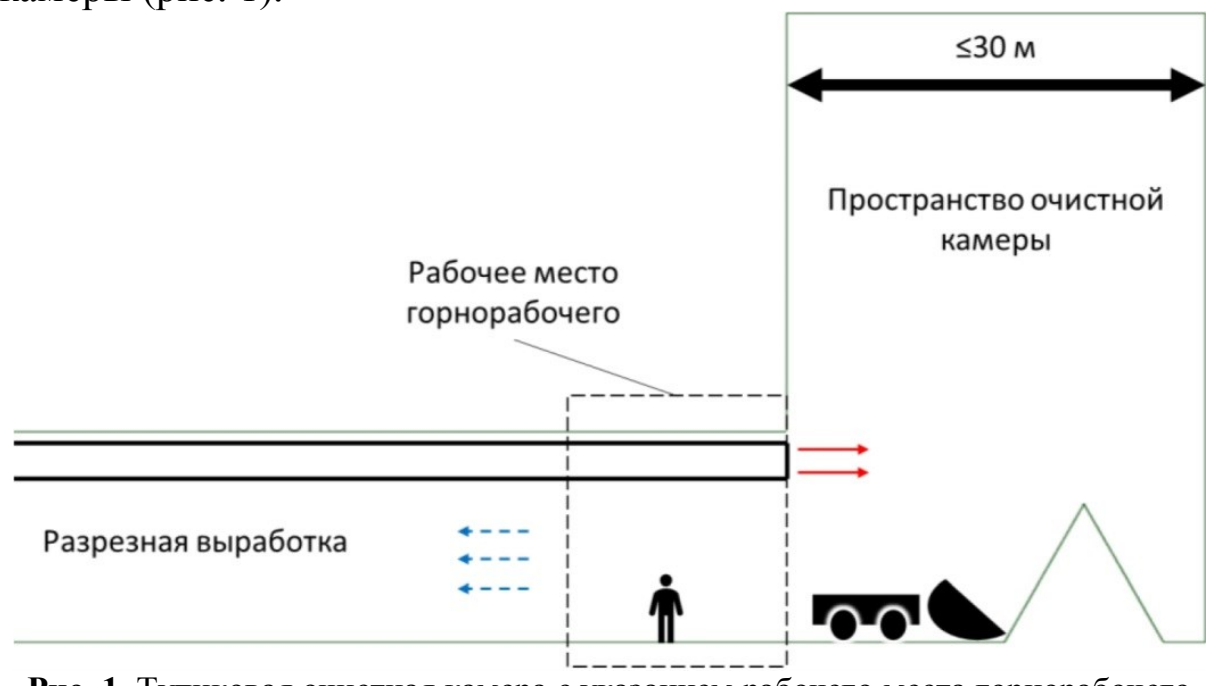

Рис. 1. Тупиковая очистная камера с указанием рабочего места горнорабочего

Целью исследования является разработка методики безопасного проветривания данного вида горных выработок в процессе отгрузки руды. Для достижения данной цели решается ряд задач:

1) разработка и верификация математической модели проветривания тупиковых очистных камер большого сечения;

2) определение параметров безопасного проветривания протяженных тупиковых очистных камер большого сечения при отгрузке руды ПДМ с ДВС;

3) определение зависимостей изменения концентраций вредных компонентов выхлопных газов в рабочей зоне от цикла работы ПДМ; 
4) оценка влияния геометрических параметров очистного пространства камеры и нарезной выработки на процесс выноса газа из пространства камеры;

5) оценка влияния аэродинамических параметров проветривания очистной камеры на процесс выноса газа из пространства камеры;

6) оценка влияния цикла работы ПДМ на процесс выноса газа из пространства камеры;

7) определение максимально возможной длины тупиковой камеры.

В данной работе представлены результаты исследования влияния различных конфигураций геометрии сечения камерообразной выработки при фиксированной длине на процесс выноса ядовитых примесей рудничного воздуха из нее в разрезную выработку, с расположенным в ней рабочим местом машиниста ПДМ. Различные конфигурации геометрии сечения камерообразной выработки имеют равную площадь поперечного сечения при различных ширине и высоте камеры.

Действующий на рудниках Талнахского рудного узла «Регламент технологических производственных процессов...» [2] запрещает нахождение горнорабочих в пространстве очистной камеры. Поэтому детальные экспериментальные исследования газовыделений в очистном пространстве камеры и его проветривания невозможны. Исследования процессов выделений вредных компонентов выхлопных газов ПДМ и проветривания очистного пространства камеры производится с использованием численного моделирования.

В настоящее время при расчетах газовыделений ядовитых компонентов выхлопных газов ПДМ используется модель изменения концентраций газа Воронина В.Н. [3]:

$$
C_{\uparrow}\left(T_{\mathrm{p}}\right)=C_{\text {max }}-\left(C_{\text {max }}-C_{\text {нач }}\right) \cdot e^{-\frac{k_{\mathrm{T}} \cdot Q}{V_{\text {пр }}} \cdot T_{\mathrm{p}}},
$$

где $C_{\max }$ - максимально возможное асимптотическое значение концентрации газа в нарезной выработке, \% по объему; $C_{\text {нач }}-$ начальная концентрация газа в выработке, \% по объему; $T_{\mathrm{p}}$ - время работы ПДМ в камере, с; $k_{\mathrm{T}}-$ безразмерный коэффициент эффективности проветривания (турбулентной диффузии свободной струи воздуха); $Q-$ количество воздуха, подаваемого в выработку, $\mathrm{m}^{3} / \mathrm{c}$.

С целью оценки применимости модели (1) в рассматриваемых условиях проведены натурные измерения в нарезной выработке, позволяющие косвенно судить о процессах в камерном пространстве. Тем не менее, полученные данные натурных измерений позволяют калибровать параметры математической модели изменения концентраций газа в камере.

На первоначальном этапе исследования определены параметры математической модели. Граничные условия турбулентности, используемые в математической модели аналогичны $[4,5]$. Шероховатость стенок выработок равна 0,03 м. Коэффициент эффективности проветривания равен 1 , его определение рассматривается в [6].

Геометрические параметры очистной камеры в зависимости от конфигурации поперечного сечения, использованные при моделировании процесса проветривания, представлены в табл. 1 .

Таблица 1

Параметры расчета для вариантов

\begin{tabular}{|c|c|c|}
\hline № варианта & Ширина камеры, $\mathbf{~}$ & Высота камеры, $\mathbf{~}$ \\
\hline 1 & 6 & 20 \\
\hline 2 & 8 & 15 \\
\hline 3 & 9 & 13,33 \\
\hline 4 & 10 & 12 \\
\hline
\end{tabular}

Результаты моделирования проветривания тупиковой очистной камеры и прилегающей к ней разрезной выработки приведены в графическим виде. Зависимости изменения концентрации ядовитых примесей (доли ПДК) в сечении рабочей зоны машиниста ПДМ от цикла работы ПДМ в пространстве очистной камеры (c) представлены на рис. 2.

На рис. 2 виден схожий характер резкого возрастания концентрации ядовитых примесей в сечении рабочего места машиниста ПДМ на первых 30 с нахождения ПДМ в пространстве камеры. На рис. 3 представлены зависимости изменения концентрации ядовитых примесей (доли ПДК) в сечении рабочего места машиниста ПДМ от времени нахождения ПДМ в пространстве очистной камеры (c) в диапазоне концентраций ядовитых примесей равном 1,2-1,65 ПДК. 


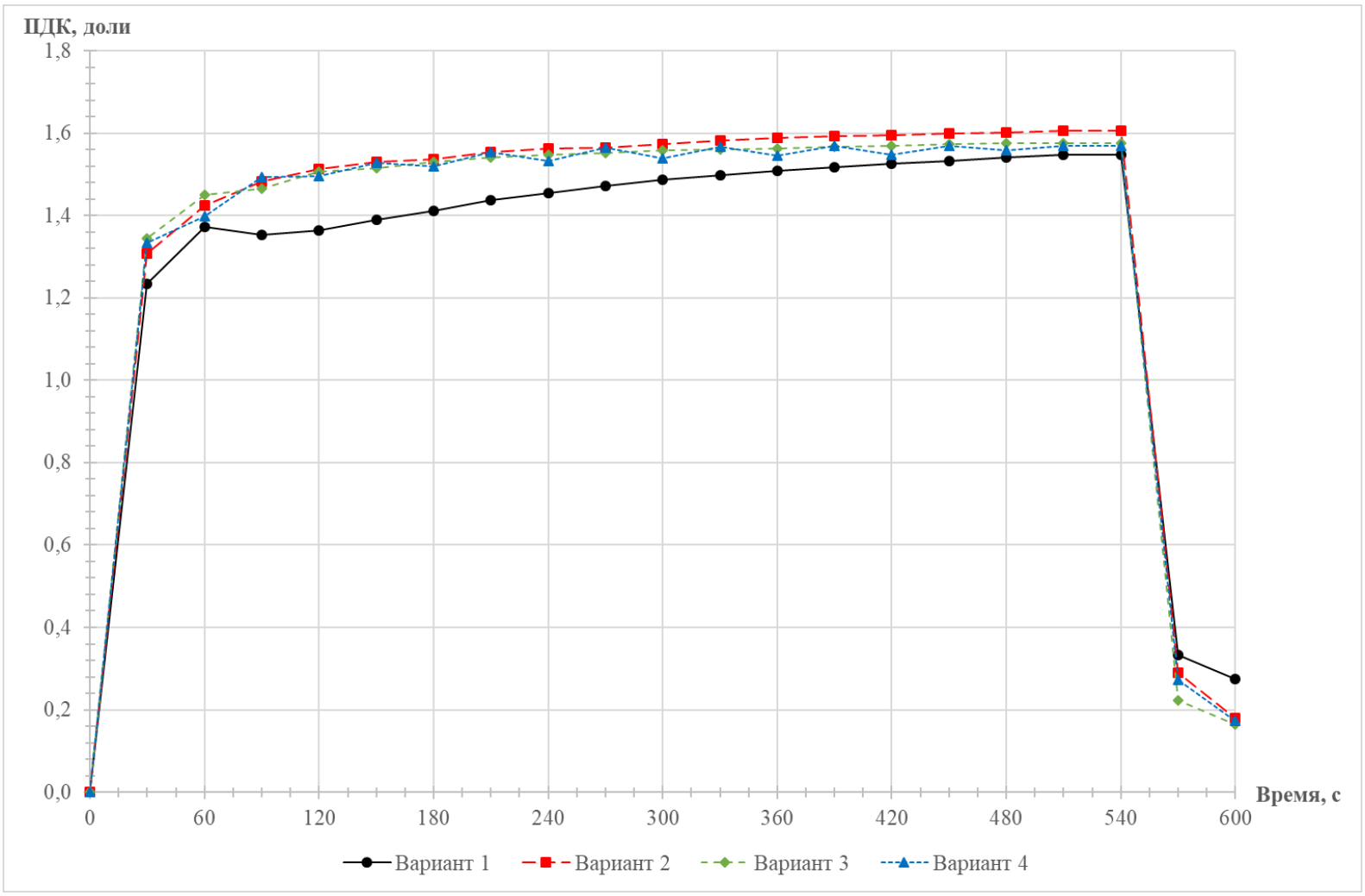

Рис. 2. Зависимости возрастания концентрации ядовитых примесей в сечении рабочей зоны машиниста ПДМ (доли ПДК) от времени нахождения ПДМ в пространстве очистной камеры (c) при различных конфигурациях поперечного сечения очистной камеры

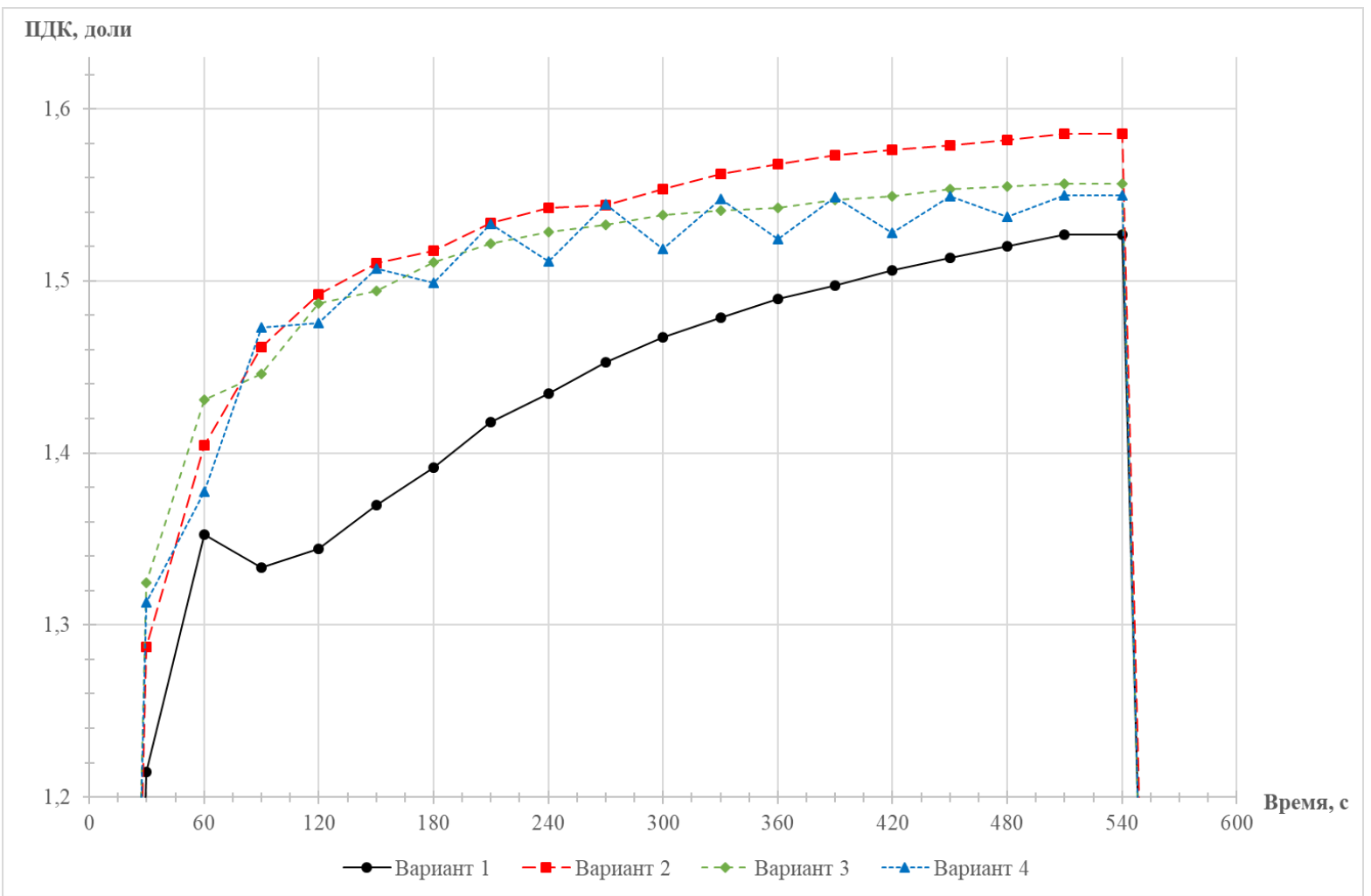

Рис. 3. Фрагмент зависимостей возрастания концентрации ядовитых примесей в сечении рабочей зоны машиниста ПДМ (доли ПДК) от времени нахождения ПДМ в пространстве очистной камеры (с) при различных конфигурациях поперечного сечения очистной камеры в диапазоне концентраций ядовитых примесей равном 1,2-1,65 ПДК 
Из рис. 3 виден схожий характер возрастания концентрации ядовитых примесей в срезе времени 30 $\div 540$ с кривых, соответствующих вариантам №№ 2-4, максимальное отклонение от наибольшего значения концентрации ядовитых примесей (красная линия, соответствующая варианту 2) составляет $3 \%$.

Черная линия, соответствующая варианту 1 , отклоняется от остальных, что объясняется наибольшей высотой камеры $(20$ м). На начальном этапе проветривания воздушный поток является не установившимся и концентрируется в зоне вблизи устья камеры. Однако затем постепенно выполаживается с соизмеримой асимптотой остальных линий, соответствующих вариантам №№ 2-4, отклонение в интервалах времени 420 $\div 540$ с составляет $4 \%$.

Отклонение значений концентрации ядовитых примесей во всем интервале времени при всех конфигурациях геометрии сечения камерообразной выработки от наибольшего значения концентрации ядовитых примесей (вариант 2) представлено в табл. 2.

Таблица 2

Отклонение значений концентрации СО от наибольшего значения

\begin{tabular}{|c|c|c|c|}
\hline Bремя, c & Bapиант 1 & Bapиант 3 & Bapиант 4 \\
\hline 0 & $0 \%$ & $0 \%$ & $0 \%$ \\
\hline 30 & $6 \%$ & $3 \%$ & $2 \%$ \\
\hline 60 & $4 \%$ & $2 \%$ & $1 \%$ \\
\hline 90 & $9 \%$ & $1 \%$ & $1 \%$ \\
\hline 120 & $10 \%$ & $0 \%$ & $0 \%$ \\
\hline 150 & $9 \%$ & $1 \%$ & $0 \%$ \\
\hline 180 & $8 \%$ & $0 \%$ & $2 \%$ \\
\hline 210 & $7 \%$ & $1 \%$ & $0 \%$ \\
\hline 240 & $7 \%$ & $1 \%$ & $2 \%$ \\
\hline 270 & $6 \%$ & $1 \%$ & $3 \%$ \\
\hline 300 & $5 \%$ & $1 \%$ & $2 \%$ \\
\hline 330 & $5 \%$ & $1 \%$ & $3 \%$ \\
\hline 360 & $5 \%$ & $2 \%$ & $2 \%$ \\
\hline 390 & $5 \%$ & $2 \%$ & $3 \%$ \\
\hline 420 & $4 \%$ & $2 \%$ & $2 \%$ \\
\hline 450 & $4 \%$ & $2 \%$ & $2 \%$ \\
\hline 480 & $4 \%$ & $2 \%$ & $2 \%$ \\
\hline 510 & $4 \%$ & $2 \%$ & \\
\hline 540 & $4 \%$ & & \\
\hline
\end{tabular}

Результаты исследования позволяют сделать вывод о независимости решения от формы поперечного сечения камеры при фиксированном объеме. Таким образом, дальнейшим направлением исследований условий проветривания тупиковых очистных камер является оценка влияния длины очистного пространства на процесс выноса газов из него при фиксированных объемах камеры.

\section{БИБЛИОГРАФИЧЕСКИЙ СПИСОК}

1. Федеральные нормы и правила в области промышленной безопасности «Правила безопасности при ведении горных работ и переработке твердых полезных ископаемых». Вып. 78: утв. 11.12.2013, № 32935. - М.: ЗАО НТЦ ПБ, 2016. - 276 с. - (Документы межотраслевого применения по вопросам промышленной безопасности и охраны недр: сер. 03).

2. Регламент технологических производственных процессов по применению камерной системы разработки с закладкой выработанного пространства и использованием дистанционно управляемого самоходного оборудования при выемке сульфидных руд на Талнахских рудниках ЗФ ОАО «ГМК «Норильский никель»: РТТП-051-2013; (с доп. № 10 от 03.06.2016 г.). - Норильск. 2013. -

3. Воронин В.Н. Основы рудничной аэро-газодинамики. - М.; Л.: Углетехиздат, 1951. - 492 с.: ил.

4. Левин Л.Ю., Исаевич А.Г., Семин М.А., Газизуллин Р.Р. Исследование динамики пылевоздушной смеси при проветривании тупиковой выработки в процессе работы комбайновых комплексов // Горн. журн. - 2015. - № 1. - С. 72-75. DOI: 10.17580/gzh.2015.01.13.

5. Казаков Б.П., Семин М.А., Мальцев С.В. Математическое моделирование проветривания панелей гипсовой шахты эжекторными установками // Изв. Тульского гос. ун-та. Науки о Земле. - 2018. - № 3. - C. 245-255.

6. Колесов Е.В. Обоснование последовательного проветривания рабочих зон нескольких тупиковых выработок // Стратегия и процессы освоения георесурсов: сб. науч. тр. Вып. 16 / ГИ УрО РАН. Пермь, 2018. - С. 291-295. DOI: 10.7242/gdsp.2018.16.78. 